Check for updates

Cite this: J. Mater. Chem. B, 2018, 6, 1095

Received 18th December 2017, Accepted 22nd December 2017

DOI: $10.1039 / \mathrm{cttb} 03261 \mathrm{~g}$

rsc.li/materials-b

\title{
Hierarchically designed hybrid nanoparticles for combinational photochemotherapy against a pancreatic cancer cell line $\dagger$
}

\author{
F. Joubert and G. Pasparakis (D)*
}

\begin{abstract}
Here, we report the formulation of hybrid nanoparticles consisting of aggregated gold nanoparticles (GNPs) impregnated into a gemcitabine-polymer conjugate matrix that exhibit synergistic photo-chemotherapeutic activity against pancreatic cancer. Well-defined, sub-100 nm hybrid NPs were successfully formulated and their photothermal conversion efficiency was evaluated, which was found to be as high as $63 \%$ in the red-visible spectrum. By varying the GNP and GEM-polymer feed, it was possible to control the red-shifting of the surface plasmon resonance at therapeutically relevant wavelengths. The hybrid NPs exhibited significant cytotoxicity against MiaPaCa-2 cells with a half-maximal inhibitory concentration $\left(\mathrm{IC}_{50}\right)$ of $0.0012 \mathrm{mg} \mathrm{mL}^{-1}$; however the $\mathrm{IC}_{50}$ decreased by a factor of 2 after the cells were irradiated with a continuous wave red laser for $1 \mathrm{~min}\left(1.4 \mathrm{~W} \mathrm{~cm}^{-2}\right)$. Although the irradiation of the aggregated GNPs loaded in the hybrid NPs produced a higher thermal effect for the same amount of non-loaded GNPs, the $I_{50}$ of the hybrid NPs was significantly lower than that of the free GNPs, hence indicating a synergistic effect of the polymer bound GEM and the GNPs.
\end{abstract}

\section{Introduction}

Pancreatic cancer is the fifth most lethal cancer with an overall survival rate of $1 \%$ after 10 years. ${ }^{1}$ In $80 \%$ of pancreatic cancer cases ${ }^{2}$ the tumours cannot be resected by surgical intervention, hence patients require a chemotherapeutic treatment. Gemcitabine (GEM), a nucleoside analogue of deoxycytidine, is currently used as the front-line drug in pancreatic cancers and has been shown to increase the overall survival rate to $21 \%$ after 5 years. ${ }^{3}$ However, GEM is metabolically unstable due to its rapid deamination in the blood stream by cytidine deaminase (CDA) and also has poor cell permeability. ${ }^{4,5}$ To compensate for these limitations, a high dose of GEM is administered resulting in severe side effects to patients such as breathlessness, neutropenia, nausea, and kidney failure. ${ }^{6}$ In recent years, GEM prodrugs have been developed with improved pharmacokinetics, cellular uptake and tumor targeting properties. ${ }^{6,7}$ of particular interest are GEM-polymer conjugates that have interesting formulation properties such as their ability to self-assemble into sub-100 $\mathrm{nm}$ nanoparticles (i.e. micelles), which is critical for deep tumor permeation of the pancreas, ${ }^{8}$ controllable release of

UCL School of Pharmacy, 29-39 Brunswick square, WC1N 1AX London, UK. E-mail: g.pasparakis@ucl.ac.uk

$\dagger$ Electronic supplementary information (ESI) available: Reaction scheme, ${ }^{1} \mathrm{H}$ NMR spectrum and GPC trace of GEM-polymer conjugate, DLS measurements, mathematical demonstration of the calculation of the heat conversion efficiency. See DOI: 10.1039/c7tb03261g
GEM, and active tumor targeting via the installation of tumor targeting ligands. ${ }^{9-15}$

Recently, photothermal therapy (PTT) has shown great potential in cancer treatment. ${ }^{16}$ PTT comprises the thermal ablation of cancer cells using a red/near-infrared (NIR) laser photoabsorber such as noble metal nanostructures, ${ }^{17,18}$ transition metal sulphides/oxides nanomaterials ${ }^{19,20}$ and other nanoagents. ${ }^{21,22}$ Hyperthermia comprises a localized increase of the temperature between 41 and $48{ }^{\circ} \mathrm{C}$ at the tumour site, which in turn induces cancer cell death via multiple apoptotic or necrotic pathways including lethal protein denaturation followed by their aggregation. ${ }^{23,24}$ More recently, PTT was combined with other therapies including radiotherapy, chemotherapy and immunotherapy. ${ }^{25}$ Photochemotherapy is particularly appealing as it harnesses the benefits of PTT and chemotherapy, which, in principle, leads to potent formulations with synergistic activity. Gold nanoparticles are excellent photoabsorbers and have been extensively utilized in PTT protocols in the form of nanosized spheres, rods, and shells owing to their excellent optical properties such as very high photothermal conversion efficiencies, and optimization of their surface plasmon resonance to deep tissue penetrating red or near-infrared wavelengths. ${ }^{18,26}$ For instance, chemotherapeutic drugs such as doxorubicin (DOX), ${ }^{27,28}$ paclitaxel, ${ }^{29-32}$ fluorouracil $^{33}$ and $\mathrm{CisPt}^{34}$ have been combined with gold-based nanostructures for the treatment of various cancers. The preparation of drug-containing GNP formulations is not always straightforward and often functional limitations 
are encountered that hamper their clinical potential, such as: (1) poor colloidal stability (leading to drug leakage, or premature disassembly in the bloodstream), (2) low drug loading per particle volume/mass, and (3) use of unsuitable chemicals for in vitro/vivo application (for example, the use of cetyltrimethylammonium bromide in the preparation of gold nanorods $s^{35}$ ). Therefore, the quest for simple $e^{36,37}$ but functionally complex formulations constitutes a major prerequisite for the translational potential of nanomedicinal photochemotherapeutics.

In this work, we report on a simple and hierarchically-defined formulation of GNPs impregnated in a polymer-gemcitabine conjugate via an efficient preparation route. The formulation exhibits certain unique characteristics that render it suitable for pancreatic cancer therapeutics. It has very high drug loading per particle, excellent colloidal stability, and clinically relevant optical properties by simply adjusting the GNP feed in the polymer matrix. We demonstrate that the formulation augments the cytotoxicity of gemcitabine due to the photothermal effect upon irradiation with a red laser and shows superior cytotoxicity to the parent drug. The proposed concept exhibits interesting formulation properties that render it suitable for direct tumor administration via, for example, catheterization, or surgical intervention, followed by laser treatment of the diseased area.

\section{Results and discussion}

\section{Synthesis of the GEM-monomer conjugate and its RAFT polymerisation}

The synthesis of the GEM-monomer conjugate and its RAFT polymerisation were reported in our previous publication; ${ }^{38}$ the GEM-monomer conjugate was prepared via a one-step amidation reaction between gemcitabine hydrochloride and mono-2methacyloyloxy ethyl succinate with an acceptable yield of 45\% (Scheme S1a, ESI $\dagger$ ). The GEM-monomer conjugate was further polymerised by RAFT using a trithiocarbonate as chain transfer agent (CTA) (Scheme S1b, ESI $\dagger$ ). A polymer with a degree of polymerisation (DP) of 100 was chosen because of its ability to self-aggregate into small nanoparticles. In fact, we have already established that short-chain polymeric GEMprodrug results in the formation of larger NPs due to weaker chain-chain interpolymer interactions. ${ }^{38}$ The GEM-polymer conjugate was successfully prepared with an average molecular weight $\left(M_{\mathrm{n}}\right)$ and dipersity $\left(\bigoplus_{\mathrm{M}}\right)$ of $36400 \mathrm{~g} \mathrm{~mol}^{-1}$ and 1.24, respectively.

\section{Preparation of gold nanoparticles (GNPs)}

GNPs were prepared using the Turkevich method; ${ }^{39}$ i.e. using citrate sodium as the reducing and stabilizing agent. The colour of the solution changed from slightly yellow to ruby indicating the successful preparation of spherical GNPs. Their size was determined using DLS and was found to be $25 \pm 7 \mathrm{~nm}$. Furthermore, their UV-vis absorption spectrum was recorded using a UV-vis spectrophotometer and their maximum absorption was measured at $527 \mathrm{~nm}$ (Fig. 2).

\section{Preparation of hybrid nanoparticles}

The rationale of the proposed formulation is based on the fact that GEM is a nucleoside analogue that binds covalently on the surface of GNPs. ${ }^{40,41}$ In addition, we hypothesized that the polymeric structure acts as a multivalent ${ }^{42}$ amplifier that could further augment the interaction of the GEM polymer with GNPs. GNPs were loaded into GEM-polymer conjugate NPs using an evaporation process protocol. The aqueous GNP suspension was used as a co-solvent with acetone to dissolve the GEM-polymer conjugate $\left(1 \mathrm{mg} \mathrm{mL}^{-1}, \mathrm{~S} 1\right)$. In order to optimise the loading capacity, different concentrations of GNPs and GEM-polymer conjugate were used, hence a series of 2-fold dilutions of the GEM-polymer conjugate ( $\mathrm{S} 2$ to $\mathrm{S} 10$ ) were prepared using a GNP suspension/acetone mixture $(50 / 50, \mathrm{v} / \mathrm{v})$ where a constant concentration of GNPs $\left(0.2 \mathrm{mg} \mathrm{mL}{ }^{-1}\right)$ was kept throughout the dilution process of the polymeric prodrug. Another set of samples $\mathrm{S} 4^{\prime}, \mathrm{S}^{\prime}, \mathrm{S} 7^{\prime}$ and $\mathrm{S} 8^{\prime}$ was prepared where the GNP concentration was doubled $\left(0.4 \mathrm{mg} \mathrm{mL}^{-1}\right)$ and the concentration of the GEM-polymer conjugate was $125,31.25,15.62$ and $7.81 \mu \mathrm{g} \mathrm{mL} \mathrm{m}^{-1}$, respectively. After the acetone was evaporated under controlled conditions, hybrid nanoparticles were formed in aqueous solution and can be seen in Fig. 1b. For the hybrid NPs of sample $S 7^{\prime}$, the amount of GEM per particle was estimated to be $0.588 \times 10^{-18} \mu \mathrm{g}$ (see the ESI $\dagger$ ).

\section{Physical characterisation of the hybrid NPs}

Visual assessment. When the GNPs are loaded in the GEMpolymer conjugate NPs, a change in colour of the solution was

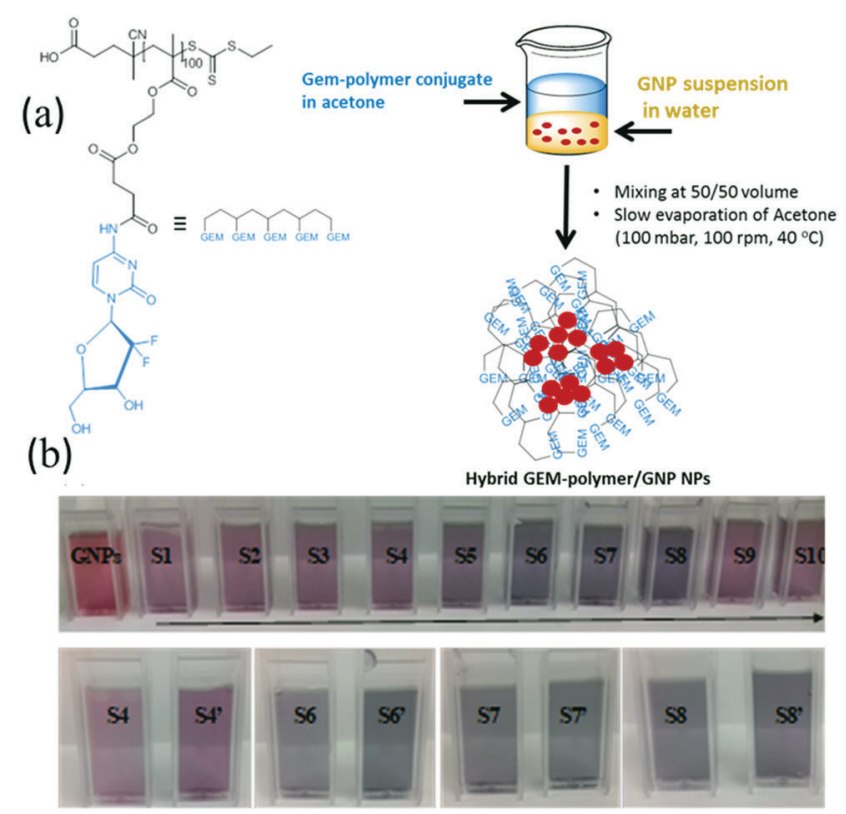

Fig. 1 Preparation of hybrid NPs; (a) schematic representation of the GEM-polymer structure and the loading of GNPs into the GEM-polymer conjugate matrix, and (b) visual appearance of the hybrid NPs in solution with different concentrations of GEM-polymer conjugate and GNPs (i.e. a series of 2-fold dilutions of GEM-polymer conjugate from S1 $\left(1 \mathrm{mg} \mathrm{mL}^{-1}\right)$ to $\mathrm{S} 10\left(0.002 \mathrm{mg} \mathrm{mL}^{-1}\right)$ where the concentration of GNPs was $0.2 \mathrm{mg} \mathrm{mL}^{-1}$; for $\mathrm{S4}^{\prime}, \mathrm{S6}^{\prime}, \mathrm{S} 7^{\prime}$ and $\mathrm{S}^{\prime}$, the concentration of GNPs was $0.4 \mathrm{mg} \mathrm{mL}^{-1}$ and the concentration of GEM-polymer conjugate was 125 , $31.25,15.62$ and $7.81 \mu \mathrm{g} \mathrm{mL}^{-1}$, respectively). 
observed. The ruby colour characteristic of the colloidal suspension of GNPs changes to a purple colour (sample S1) and as the concentration of GEM-polymer conjugate decreased, the colour of the colloidal suspension became darker with a blue hue (sample S8) due to the loading of the GNPs into the GEMpolymer conjugate matrix. A decrease of the concentration of the GEM-polymer conjugate results in a decrease of the number of GEM-polymer conjugate NPs relative to the number of GNPs, which was kept constant, hence increasing the loading of GNPs inside the GEM-polymer conjugate NPs; this in turn increases the GNP aggregates inside the polymeric capsules. However, further lowering the concentration of the GEM-polymer conjugate (sample S9 and S10) resulted in a return to a purple/ruby colour because, presumably, the GNP loading capacity had reached a maximum limit. On the other hand, when the concentration of GNPs was doubled (samples $\mathrm{S}^{\prime}, \mathrm{S}^{\prime}, \mathrm{S} 7^{\prime}$ and $\mathrm{S} 8^{\prime}$, Fig. 1b), the colour of the colloidal suspension turned darker (in the case of sample $\mathrm{S}^{\prime}, \mathrm{S} 6^{\prime}$ and $\mathrm{S}^{\prime}$ ) because of the increase of the GNPS loading inside the polymeric matrix, and the colour change from blue to purple for $\mathrm{S}^{\prime}$ was again due to the limitation of the capacity of the capsule.

UV-vis spectroscopy analysis. A UV-vis spectrum was recorded for each sample (Fig. 2). As expected, the UV-vis absorption band of all samples moved to higher wavelengths and became broader compared to that of GNPs. The shift of the UV-vis absorption band toward higher wavelengths increased by decreasing the concentration of the GEM-polymer conjugate NPs (up to sample S7). The surface plasmon resonance (SPR) bands for samples S1, S2, S3, S4 and S5 were all shifted to $\sim 550 \mathrm{~nm}$
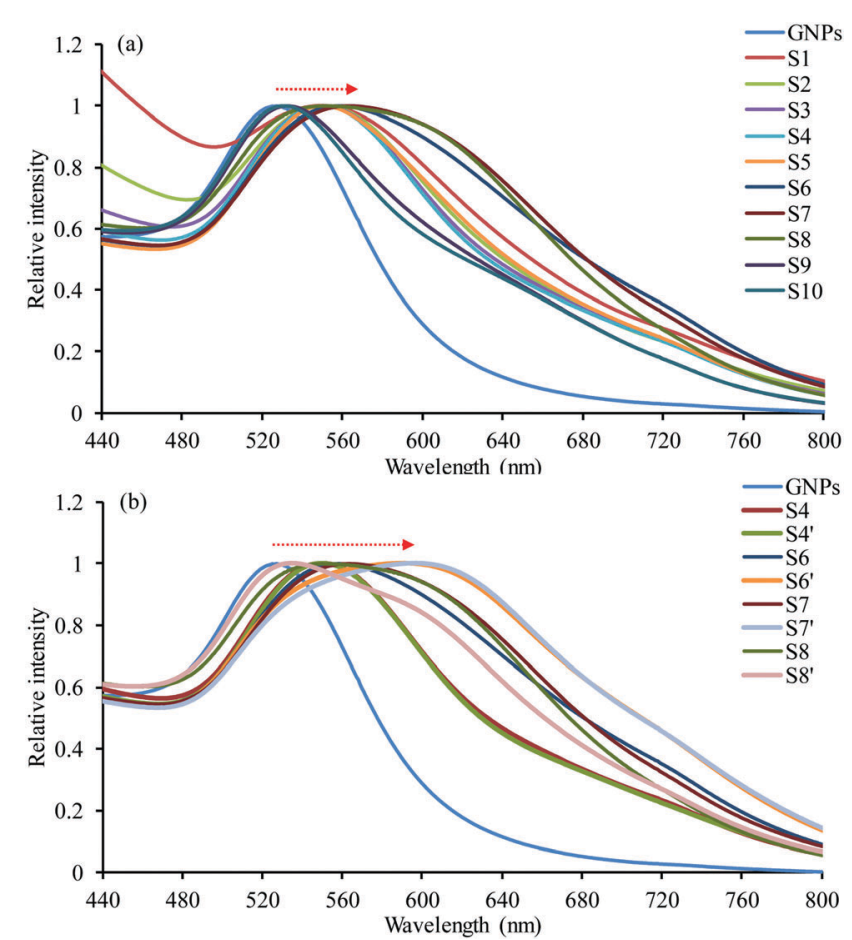

Fig. 2 UV-vis spectra of GNPs and hybrid NPs highlighting the evidence of the influence of the concentration of (a) GEM-polymer conjugate and (b) GNPs on the SPR band. compared to that of GNPs at $527 \mathrm{~nm}$. There were no significant differences between the spectra of those samples because the encapsulated GNPs only partially aggregated inside the NPs due to their low number and/or the high number of GEM-polymer conjugate NPs. For sample S7, the SPR was significantly redshifted to $563 \mathrm{~nm}$, indicating more robust aggregation of GNPs inside the GEM-polymer conjugate NPs (Fig. 2a). Furthermore, the SPR was much broader compared to other absorption bands, which corroborated with the aggregation of GNPs inside the GEM-polymer conjugate NPs. For samples S9 and S10, the SPR blue-shifted to $533 \mathrm{~nm}$ due to an insufficient number of polymer NPs to encapsulate GNPs efficiently. The UV-vis absorption band of sample $\mathrm{S}^{\prime}{ }^{\prime}$ remained the same as that of sample S4 although the concentration of GNPs was doubled when preparing $\mathrm{S}^{\prime}$. This is probably due to the stability of the GNPs inside the GEM-polymer conjugate NPs. However, an increased concentration of GNPs for the preparation of $\mathrm{S}^{\prime}{ }^{\prime}$ and $\mathrm{S}^{\prime}{ }^{\prime}$ resulted in an increased red-shift (Fig. 2b). The SPR of S7' shifted significantly to $597 \mathrm{~nm}$ because GNPs effectively aggregated inside the GEM-polymer conjugate NPs. On the other hand, the absorption band of sample $\mathrm{S}^{\prime}{ }^{\prime}$ was shifted back towards lower wavelengths ( $c a .535 \mathrm{~nm}$ ) although the concentration in GNPs was doubled; this is because most of the GNPs remained outside the GEM-polymer conjugate NPs.

Size measurements. The size and size distribution of the hybrid NPs of the different samples was measured using DLS (Fig. 3). The polydispersity (PDI) values of the samples range from 0.035 to 0.325 indicating a relatively narrow size distribution of the hybrid NP suspension. For sample S1, the average hydrodynamic diameter $\left(D_{\mathrm{h}}\right)$ of the hybrid NPs was found to be $387 \pm 15 \mathrm{~nm}$. Interestingly, the $D_{\mathrm{h}}$ of GEM-polymer conjugate NPs increased by $300 \mathrm{~nm}$ when prepared in the presence of the GNP suspension. Perhaps the chain-chain interpolymer interactions responsible for the formation of the GEM-polymer conjugate NPs become weaker when GNPs are present in the NP formation process. Interestingly, the $D_{\mathrm{h}}$ of the hybrid NPs decreased as the concentration of GEM-polymer conjugate decreased. For sample S8, the $D_{\mathrm{h}}$ of the hybrid NPs was found to be the same as the GEM-polymer conjugate NPs, and two particle populations were observed in samples S9 and S10 (Fig. 3a): $\sim 20 \mathrm{~nm}$ and $\sim 100 \mathrm{~nm}$, corresponding to free residual GNPs and hybrid NPs, respectively. It seems that the chainchain interpolymer interactions became more dominant as the concentration of GEM-polymer conjugate decreased in the presence of GNPs, hence forming smaller hybrid NPs. For sample $\mathrm{S}^{\prime}$ (Fig. 3b), where the concentration of GNPs was doubled, the size of the hybrid NPs remained similar to that of sample S4, probably because of an excess of GNPs compared to polymeric NPs. However, increasing the concentration of GNPs in samples $\mathrm{S6}^{\prime}$ and $\mathrm{S} 7^{\prime}$ (Fig. $3 \mathrm{c}$ and d) resulted in an increased size of the hybrid NPs of $80 \mathrm{~nm}$. In fact, the hybrid NPs in sample $\mathrm{S7}^{\prime}$ had a $D_{\mathrm{h}}$ of $218 \pm 65 \mathrm{~nm}$ whereas their $D_{\mathrm{h}}$ was $138 \pm 24 \mathrm{~nm}$ in sample S7. The GNPs disturbed the chain-chain interpolymer interactions, hence increasing the loading of GNPs inside the GEM-polymer conjugate NPs resulting in the formation of larger hybrid NPs. For sample $\mathrm{S}^{\prime}$, the $D_{\mathrm{h}}$ of the hybrid NPs became 

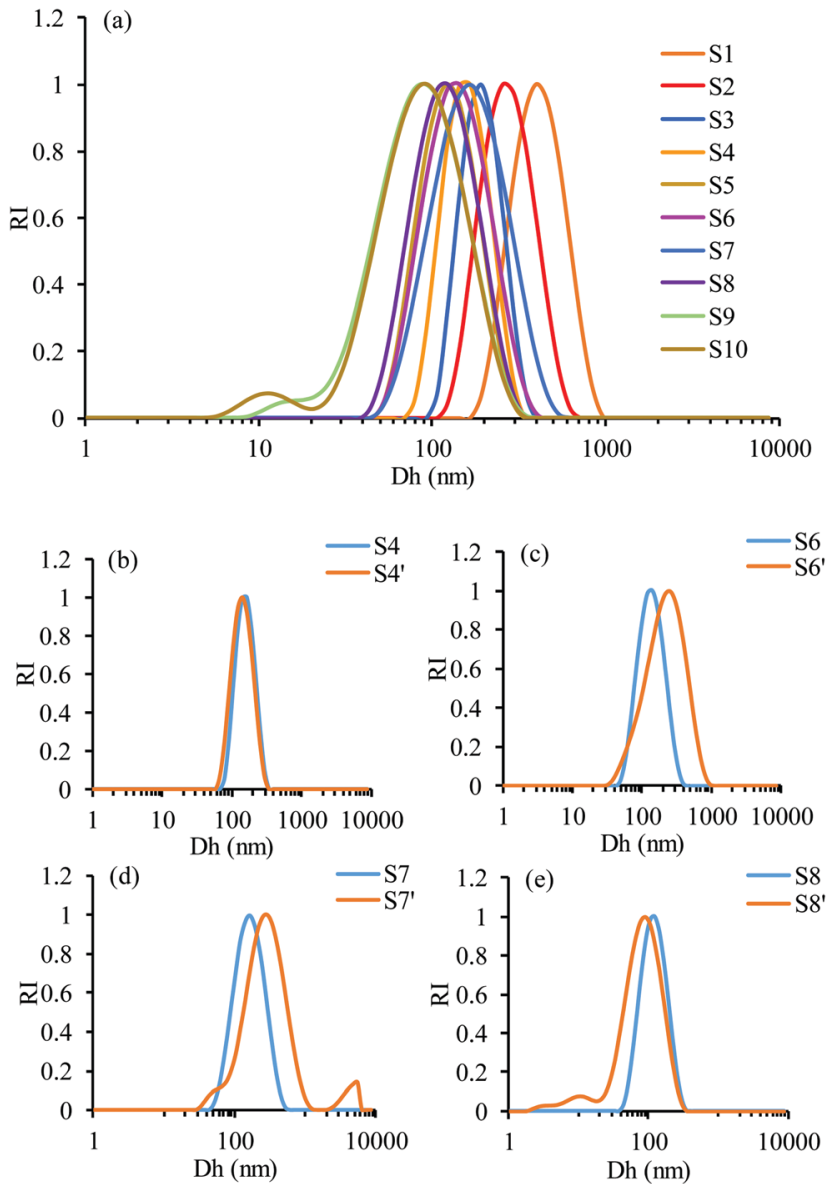

Fig. 3 DLS measurements of the hybrid NPs showing the influence of the concentration of (a) GEM-polymer conjugate and (b-e) GNPs, on the average hydrodynamic diameters.

slightly smaller indicating the limit of the loading capacity of GEM-polymer conjugate NPs for those concentrations of GEM-polymer conjugate (Fig. 3e).

TEM imaging of the hybrid NPs. TEM images of the hybrid NPs of samples S1, S7 and S7' are displayed in Fig. 4. Generally, the $D_{\mathrm{h}}$ values were slightly lower than the $D_{\mathrm{h}}$ values measured using DLS because of the sample dehydration onto the TEM grids. The decrease of particle size by decreasing the concentration of the GEM-polymer conjugate was confirmed. In fact, the $D_{\mathrm{h}}$ of sample S1 was found to be $345 \pm 69 \mathrm{~nm}$ whereas for sample S7, the $D_{\mathrm{h}}$ was $115 \pm 14 \mathrm{~nm}$. Furthermore, the TEM image of sample S7 (Fig. 4b) highlights a higher GNP loading into the GEM-polymer NPs compared to sample S1 (shown in Fig. 4a). For sample S7', where the concentration of GNPs was doubled for the preparation of the hybrid NPs, the $D_{\mathrm{h}}$ value was found to be $113 \pm 14 \mathrm{~nm}$, which is similar to the $D_{\mathrm{h}}$ value measured for the hybrid NPs of sample S7. However, the $D_{\mathrm{h}}$ value is much lower than the $D_{\mathrm{h}}$ measured using DLS. The TEM image of sample $\mathrm{S}^{\prime}$ (Fig. 4c) shows a partial interparticle aggregation, which could explain the higher $D_{\mathrm{h}}$ value measured by DLS. Furthermore, the PDI value measured by DLS was found to be 0.3 for sample $\mathrm{S}^{\prime}$ whereas the PDI value was 0.177 for sample S7. The increase of the polydispersity value (a)
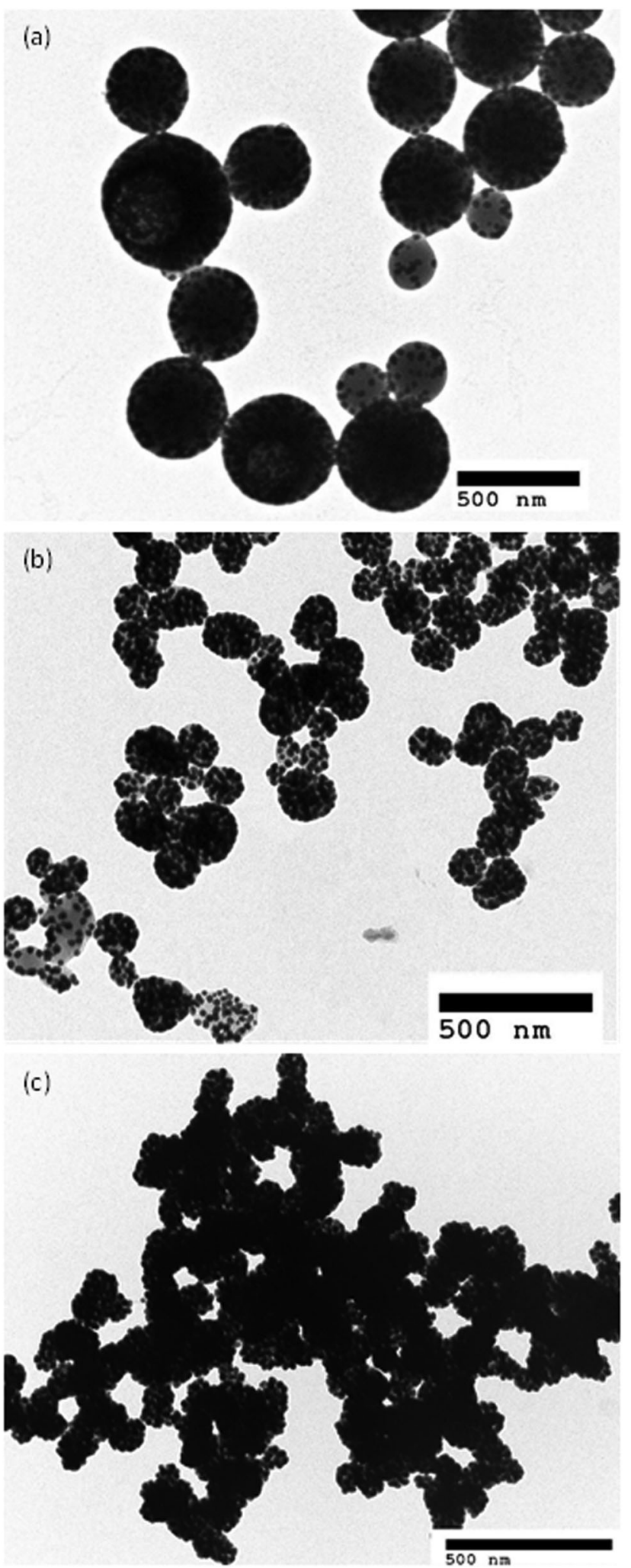

Fig. 4 TEM images of the hybrid NPs from sample (a) S1, (b) S7 and (c) S7'.

demonstrated the coagulation of the hybrid NPs in sample S7'. Finally, GNPs formed very dense aggregate clusters inside GEMpolymer conjugate NPs in sample S7', indicating a maximum loading of GNPs. The nearly complete absence of non-loaded 
GNPs in the samples should also be noted, which was also evidenced in the DLS data, which further supports the efficiency of our encapsulation protocol.

\section{Colloidal stability of hybrid NPs}

The colloidal stability of the hybrid NPs was assessed using DLS. For each sample, the $D_{\mathrm{h}}$ and PDI were measured after being left at room temperature without stirring for 16 days (Fig. S1, ESI $\dagger$ ). For samples $\mathrm{S} 1$ to $\mathrm{S} 10, \mathrm{~S} 4^{\prime}, \mathrm{S} 6^{\prime}$ and $\mathrm{S} 8^{\prime}$, relatively similar PDI and $D_{\mathrm{h}}$ values were measured, indicating a good stability of the hybrid NPs over the tested time frame. However, the PDI and $D_{\mathrm{h}}$ values of sample $\mathrm{S} 7^{\prime}$ were lower after 16 days. A $D_{\mathrm{h}}$ value of $144 \mathrm{~nm}$ was measured and was similar to the $D_{\mathrm{h}}$ value determined by TEM. Furthermore, a decrease of the PDI to 0.236 demonstrated a narrower size distribution of sample $S 7^{\prime}$ after 16 days compared to the freshly prepared batch. This may due to the elimination of the interparticle coagulation leading to a narrower dispersed NP population. Furthermore, it should be noted that the stability of the GEM-polymer conjugate NPs was demonstrated in our previous work. ${ }^{38}$ The release of GEM was quantified in neutral and acidic conditions using HPLC. GEM was not released in neutral conditions for 30 days but was released up to $80 \%$ under acidic conditions via a 2-step hydrolysis mechanism. Hence, the hybrid NPs are most likely to follow the same pattern regarding GEM release. Therefore, it is reasonable to assume that the colloidal stability is dominated by possible changes in interpolymer chain-chain interactions rather than hydrolysis of the NPs over the tested timeframe.

\section{Evaluation of the photothermal effect}

Having established all the formulation parameters to optimise the size of the NPs, their GNP content as well as their colloidal stability, we shortlisted sample $S 7^{\prime}$ as the potentially most potent for photothermal therapy owing to its large red-shifting of the SPR. To evaluate the photothermal effect, suspensions of sample $S 7^{\prime}$, GNPs, and water as a control were irradiated using a continuous wave $640 \mathrm{~nm}$ laser for $10 \mathrm{~min}$ and the temperature was recorded every minute (Fig. 5a). The concentration of $S 7^{\prime}$ and the GNPs was pre-adjusted using UV-vis spectrophotometry in order to have a similar amount of NPs; the absorbance at $640 \mathrm{~nm}$ for the GNPs and hybrid NPs was 0.1 and 0.72 , respectively.

The temperature of the hybrid NP solution increased very rapidly in a time-dependant manner during the first few minutes and subsequently reached a plateau. In fact, the temperature of the hybrid NP solution increased by $12.3{ }^{\circ} \mathrm{C}$ in 10 minutes while the temperature of the GNP suspension and water only increased by $2.5{ }^{\circ} \mathrm{C}$ and $1.2{ }^{\circ} \mathrm{C}$, respectively. Hence, the hybrid NPs converted light into thermal energy very efficiently. To determine the photothermal conversion efficiency, the cooling of the suspension-containing hybrid NPs and GNPs was recorded for 10 minutes after the laser was turned off (Fig. 5c and Fig. S2a, $\mathrm{ESI} \dagger$ ). From the cooling phase, a linear time data versus negative logarithm of driving force temperature plot was obtained (Fig. 5c and Fig. S2b, ESI $\dagger$ ) and was used to calculate the photothermal heat conversion $(\eta)$ as described by Hu et $a l^{43}$ (see the ESI $\dagger$ ). The conversion efficiency $(\eta)$ does not represent the ability of
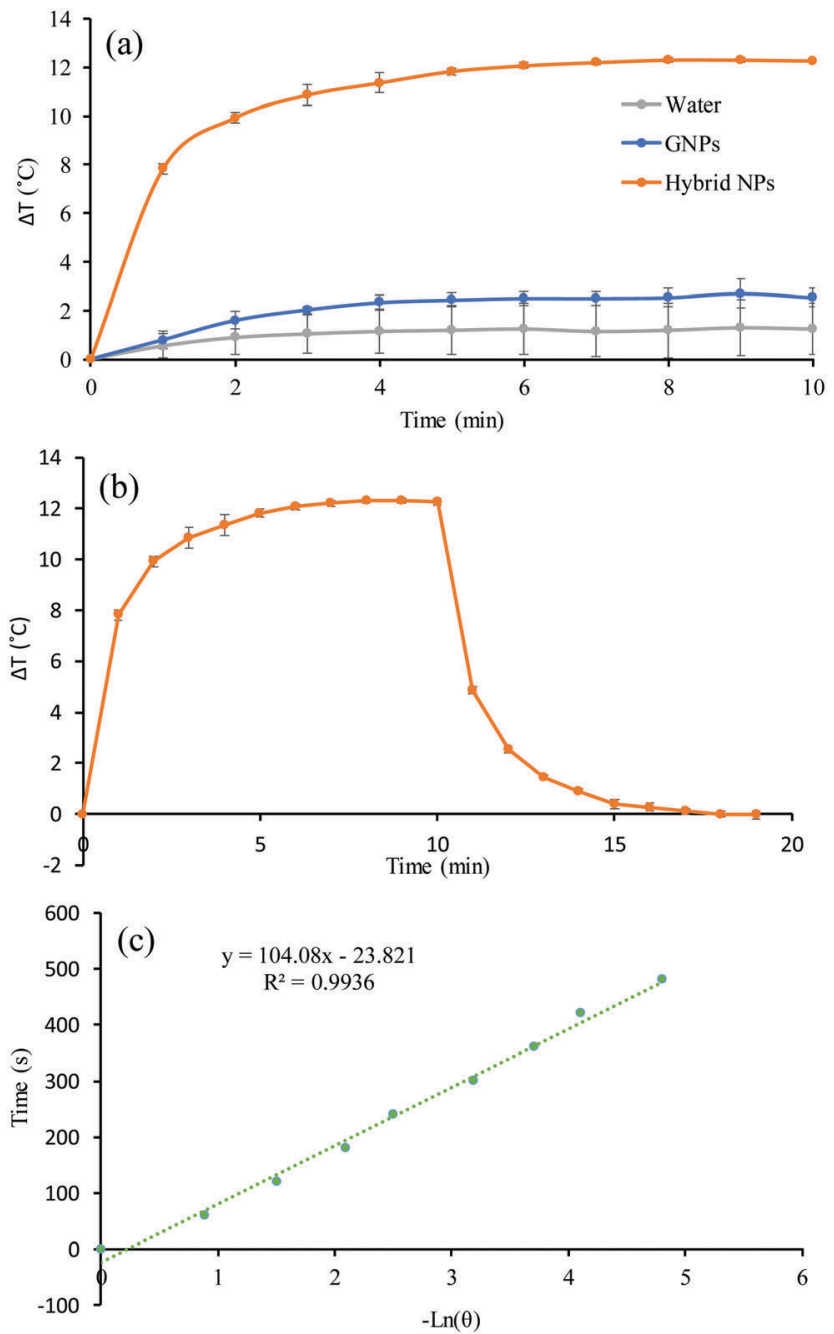

Fig. 5 (a) Temperature evolution as a function of the irradiation time, (b) photothermal effect of the irradiation of the aqueous dispersion of GNPs and hybrid NPs of sample S7' for 10 min with a red laser $\left(640 \mathrm{~nm}, 0.8 \mathrm{~W} \mathrm{~cm}^{-2}\right)$ and then the laser was turned off and (c) linear time data from the cooling period versus negative natural logarithm of driving force temperature, which was obtained from the cooling phase of Fig. $5 b$.

the NPs to generate heat but defines the ability of the NPs to dispose of the energy either by scattering or absorption. The $\eta$ of the hybrid NPs and GNPs was found to be $63 \%$ and $54 \%$, respectively, which is considerably higher than red/NIR absorbing gold nanoshells $(13 \%)$, gold nanorods $(22 \%)$, and even more efficient than large GNP aggregates $(52 \%) .{ }^{44}$ This excellent photothermal conversion capacity is attributed to the nanoconfinement effect of the formulation that is achieved by the polymer matrix that drives the clustering of the GNPs.

\section{In vitro cytotoxicity against MiaPaCa-2 cells}

The cytotoxicity of the hybrid NPs of sample $\mathrm{S}^{\prime}{ }^{\prime}$ was tested in vitro against a model pancreatic cell line (MiaPaCa-2) in order to compare their half-maximal inhibitory concentration $\left(\mathrm{IC}_{50}\right)$ with that of GEM, the GNPs and the GEM-polymer conjugate NPs (Fig. 6a), which was obtained from the evolution of the cell viability as a function of the concentration of GEM (Fig. S5a, ESI $\dagger$ ) and 

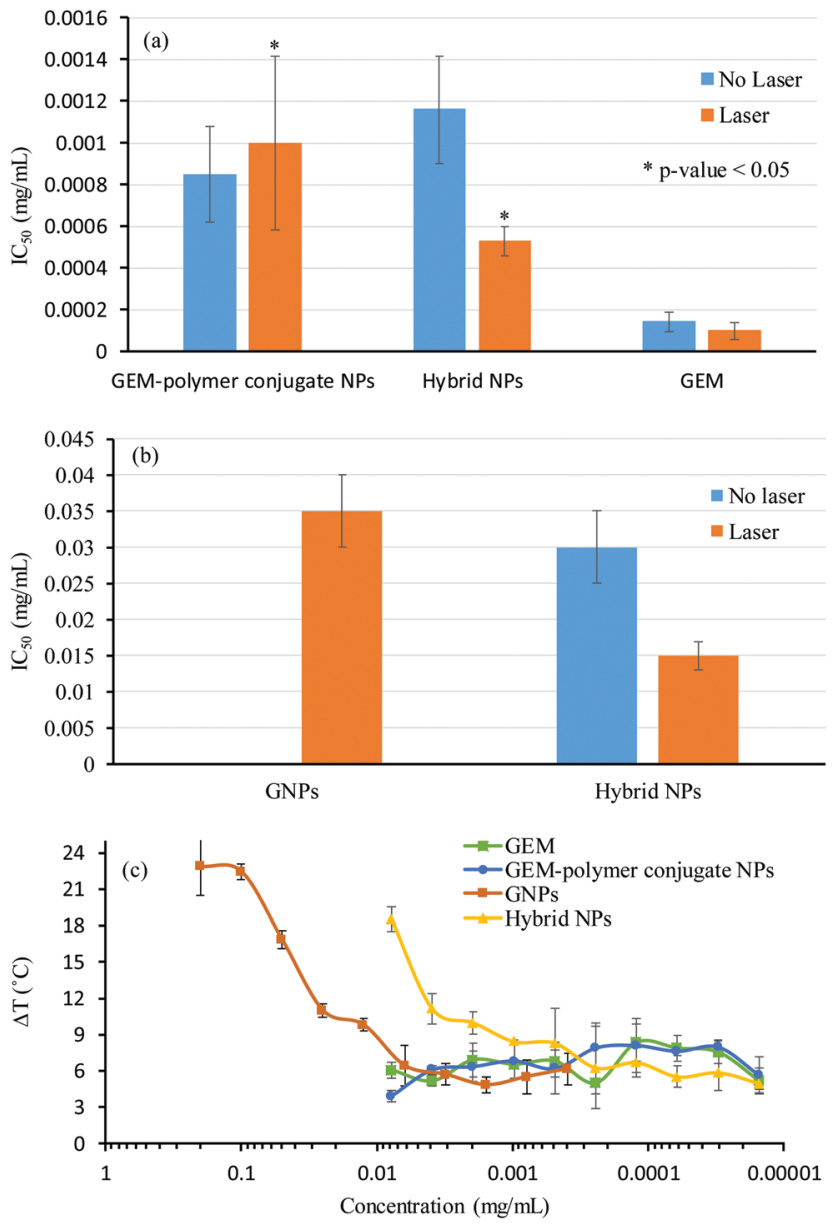

Fig. 6 (a) IC 50 relative to GEM concentration of GEM-polymer conjugate, hybrid NPs of sample S7' and GEM, (b) IC 50 relative to GNP concentration of GNPs and hybrid NPs of sample S7' with and without laser irradiation and (c) temperature evolution as a function of the concentration of GEM or GNPs.

GNPs (Fig. S5b, ESI $\uparrow$ ). It should be noted that the cell viability was not influenced by laser irradiation alone. Furthermore, the influence of the photothermal effect on the $\mathrm{IC}_{50}$ was evaluated by irradiating cells for $1 \mathrm{~min}\left(640 \mathrm{~nm}, 1.4 \mathrm{~W} \mathrm{~cm}^{-2}\right.$ ) (Fig. 6b); in addition, the maximum temperature obtained in each well during laser irradiation was recorded for each dilution (Fig. 6c).

The $\mathrm{IC}_{50}$ of GEM was found to be $0.0001 \mathrm{mg} \mathrm{mL}^{-1}$ and was not influenced by laser irradiation (Fig. 6a). Again, for the GEMpolymer conjugate NPs, the $\mathrm{IC}_{50}$ values were relatively similar to those without irradiation, i.e. $\sim 0.001 \mathrm{mg} \mathrm{mL}^{-1}$ (Fig. 6a). As expected, the $\mathrm{IC}_{50}$ values of the GEM-polymer conjugate NPs were higher than the $\mathrm{IC}_{50}$ values of GEM and this is due to the slow release of GEM via hydrolysis of the GEM-polymer conjugate. ${ }^{38}$ The release of GEM is triggered via a change in $\mathrm{pH}$ and the presence of enzymes such as cathepsin B capable to cleave the amide and ester linker. In our previous work, ${ }^{38}$ the addition of cathepsin $\mathrm{B}$ in the acidic buffer significantly increased the overall rate of GEM release from the GEM-polymer conjugate. For the hybrid NPs, an $\mathrm{IC}_{50}$ value of $0.001 \mathrm{mg} \mathrm{mL}^{-1}$ was measured, which interestingly decreased by a factor 2 (i.e. $0.0005 \mathrm{mg} \mathrm{mL} \mathrm{m}^{-1}$ ) when cells were irradiated for $1 \mathrm{~min}$, hence we hypothesized that the cytotoxicity of the hybrid NPs was improved due to the hyperthermia effect as the measured temperature in the well after $1 \mathrm{~min}$ of irradiation was $45{ }^{\circ} \mathrm{C}$ (Fig. 6c). In order to deconvolute the hyperthermia driven cytotoxicity from cell death caused by GEM, we conducted a series of control experiments: we first tested the toxicity of GNPs, which were found not to be cytotoxic, however they became slightly toxic with a high $\mathrm{IC}_{50}$ value of $0.035 \mathrm{mg} \mathrm{mL}^{-1}$ when irradiated using the laser (Fig. 6b). Surprisingly, GNPs generated a $\Delta T$ increase of $15{ }^{\circ} \mathrm{C}$, reaching a temperature of $52{ }^{\circ} \mathrm{C}$, which caused the increase of cell death under these experimental conditions. Although the photothermal effect generated by the GNPs was significantly more pronounced than that of the hybrid NPs, the $\mathrm{IC}_{50}$ of the hybrid NPs remained considerably lower than that of the GNPs, implying that the high cytotoxicity of this sample can be attributed to the synergetic cytotoxic effect between GEM and GNPs in the hybrid NPs (Fig. 6b). The combination index (CI) was calculated from the $\mathrm{IC}_{50}$ values of the GEM-polymer conjugate NPs, GNPs and the hybrid NPs using the Chou-Talalay method (see the ESI $\dagger$ ) ${ }^{45}$ The CI value is representative of a synergetic $(\mathrm{CI}<1)$, additive $(\mathrm{CI}=1)$ or antagonistic (CI > 1) effect. The CI of the hybrid NPs was found to be 0.8 which indicates a strong synergetic cytotoxicity effect.

Optical microscopy images of MiaPaCa-2 cells, which were previously incubated with GNPs and hybrid NPs at their $\mathrm{IC}_{50}$ concentrations, were recorded (Fig. 7). GNPs could easily be

(a) GNPs

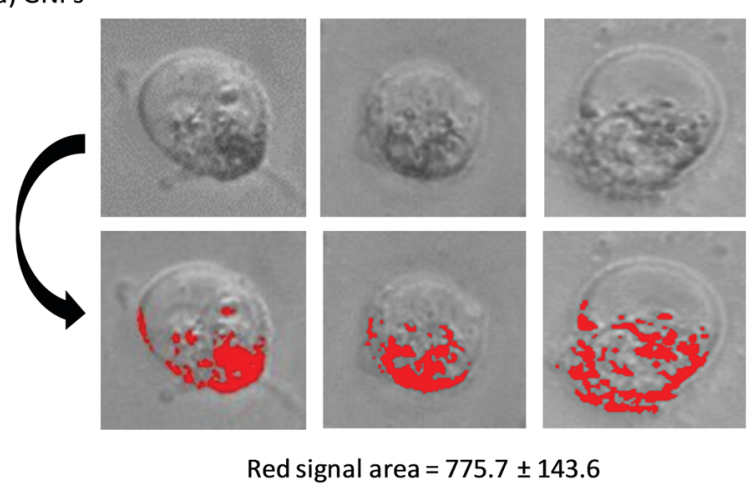

(b) Hybrid NPs

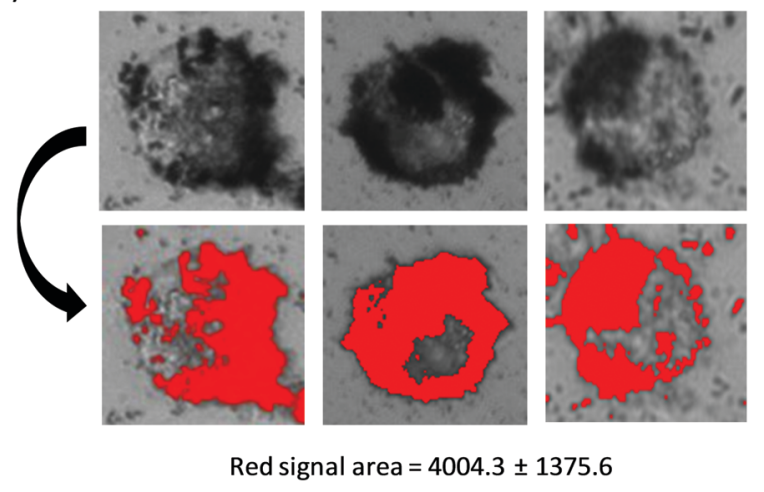

Fig. 7 Optical microscopy images of MiaPaCa-2 incubated with GNPs and hybrid NPs after $72 \mathrm{~h}$ at $37^{\circ} \mathrm{C}$ with $5 \% \mathrm{CO}_{2}$. 
traced due to their characteristic black hue, and hence a visual assessment of the GNPs per cell could be digitally converted to red pixel signal with the use of imageJ software. In the case of the GNPs (Fig. 7a), the number of GNPs per cell seems limited and the surface area covered by GNPs (red surface) was estimated to be 775.7 pixel units. On the other hand, for the hybrid NPs (Fig. 7b), a significantly higher number of GNPs surrounding each cell was observed indicating a considerably stronger affinity of the hybrid NPs for the cell membranes. In fact, the surface area covered by GNPs was increased by a factor 5 in the case of the hybrid NPs and was found to be 4004.3 pixel units. This finding was very surprising because the concentration of GNPs for the hybrid NPs was lower (i.e. $0.015 \mathrm{mg} \mathrm{mL}^{-1}$ ) compared to the concentration used in the case of GNPs only $\left(0.035 \mathrm{mg} \mathrm{mL}^{-1}\right)$. These results could possibly be attributed to the high affinity of the polymer towards the cell membrane, which could be of multivalent nature and certainly merits further biophysical investigation in detail to fully elucidate the exact selective uptake mechanism and how it impacts the cytotoxicity effect.

Next, the mode of cell death was investigated using a staining protocol that distinguishes necrosis from apoptosis. Cells undergoing apoptosis maintain their membrane integrity and inflammatory response is prevented whereas the cell membrane of necrotic cells disintegrates and their damage-associated biomolecular pathway induces an inflammatory response. Under laser exposure, the cell response can vary and most studies ${ }^{46-48}$ have reported necrosis as the dominant cell death mechanism of PTT, especially for high temperatures $\left(>50{ }^{\circ} \mathrm{C}\right) \cdot{ }^{49,50}$ Here, the ratio of necrotic to apoptotic cells was determined before and after laser irradiation for GEM, GNPs, GEM-polymer conjugate and hybrid NPs at their $\mathrm{IC}_{50}$ concentrations (Fig. 8). Without light exposure, cells underwent mainly apoptosis (i.e. at least $70 \%$ of the total dead cells) when in contact with GEM, GNPs, GEMpolymer conjugate NPs and hybrid NPs. In the case of GEM and GNPs, the cell death mechanism was not affected under light exposure. In contrast, the ratio of necrotic to apoptotic cells increased to $c a$. $50-60 \%$ for GEM-polymer conjugate NPs and hybrid NPs under light exposure. To evaluate the photothermal effect, the temperature was recorded after the irradiation (Fig. 8). An increase of the temperature ranging from $3.6{ }^{\circ} \mathrm{C}$ up to $10.2{ }^{\circ} \mathrm{C}$ was observed but there was no clear evidence of corroboration

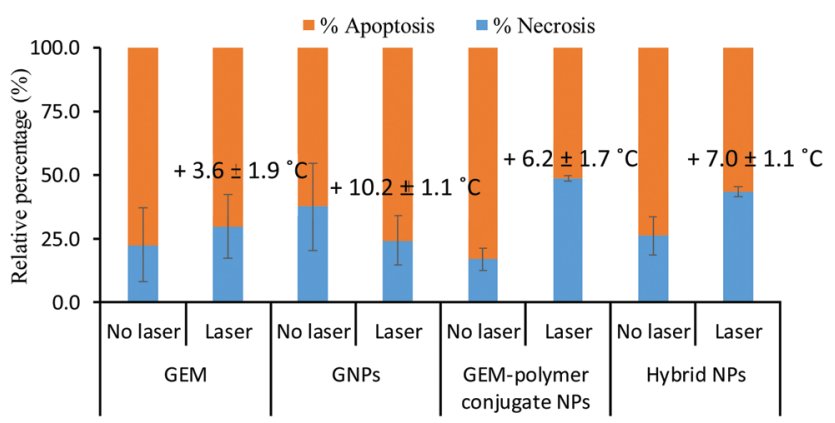

Fig. 8 Necrotic versus apoptotic cell percentage for GEM, GNPs, GEMpolymer conjugate NPs and hybrid NPs of sample S7' with and without irradiating cells. between the thermal effect and the cell death pathway. However, if we consider GEM or GNP treated cells where it is observed that the apoptosis to necrosis ratio remains at $c a$. 70:30 irrespective of laser irradiation, it is reasonable to conclude that the cell death pathway in the samples of the GEM-polymer conjugate NPs, and hybrid NPs (Fig. 8) should be attributed to direct synergism (and not to additive cytotoxicity events) with photothermally induced heat given that these are the only samples where the apoptosis: necrosis ratio changes significantly, from $80: 20$ to $50: 50$, and from $75: 25$ to $60: 40$, respectively.

\section{Experimental}

\section{Materials}

Gemcitabine hydrochloride (GEM-HCl) $(\geq 98 \%)$ was purchased from Carbosynth Ltd. 1-(3-Dimethylaminopropyl)3-ethylcarbodiimide hydrochloride (EDC), mono-2-methacyloyloxy ethyl succinate, anhydrous dimethylformamide (DMF), pyridine, sodium bicarbonate $\left(\mathrm{NaHCO}_{3}\right)$, magnesium sulfate $\left(\mathrm{MgSO}_{4}\right)$, 4,4'-azobis(4-cyanovaleric acid) (ACVA) and gold(III) chloride trihydrate were purchased from Sigma Aldrich. Trisodium citrate dehydrate was bought from Alfa Aesar. The chain transfer agent (CTA) (4-cyanopentanoic acid)ylethyl trithiocarbonate (CPAETC) was prepared according to a previously reported procedure. ${ }^{51}$ Hydroxybenzotriazole ( $\mathrm{HOBt}$ ) was purchased from AnaSpec Inc. Deuterated dimethylsulfoxide (DMSO- $\mathrm{d}_{6}$ ) was supplied from Cambridge Isotope Laboratories Inc. Methanol (MeOH), dichloromethane (DCM) and acetone were purchased from VWR International. Dulbecco's modified eagle medium (DMEM), fetal bovine serum (FBS), glutamine, penicillin, resazurin and phosphonate buffered solution (PBS) were supplied from Sigma Aldrich. TEM grids were bought from EM Resolutions. The apoptosis and necrosis quantification kit plus was supplied from Biotium.

\section{Characterisation}

Solution state NMR was performed using a Bruker Avance 400 spectrometer. An LCMS-2020 instrument from Shimadzu was used to determine the molecular mass of the GEM-monomer conjugate. The DLS measurements were performed using a zetasizer nano-ZS Malvern instrument. Size exclusion chromatography (SEC) was conducted with DMF as the mobile phase containing $5 \mathrm{mM} \mathrm{NH}_{4} \mathrm{BF}_{4}$ additive at $70{ }^{\circ} \mathrm{C}$ with a flow rate of

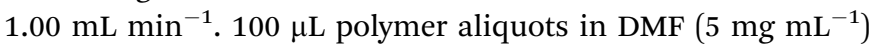
were injected in a Viscotek system equipped with a refractive index (RI) detector. Poly(methyl methacrylate) (PMMA) standards were used for calibration and OMNISEC software was used to determine the average molecular weight $\left(M_{\mathrm{n}}\right)$ and index of polydispersity $\left(D_{\mathrm{M}}\right)$. A Cary $100 \mathrm{UV}$-vis spectrophotometer from Agilent Technologies was used to record UV-vis absorption spectra. A SpectraMax ${ }^{\mathbb{R}}$ M2e multimode microplate reader was used to measure the fluorescence and absorbance of the samples. TEM images were recorded using a Philips/FEI CM120 Bio Twin Transmission Electron Microscope. Polymer samples of $1 \mathrm{mg} \mathrm{mL} \mathrm{m}^{-1}$ in double distilled water were directly dispensed onto TEM grids and left to dry without staining. A red laser 
(640 nm, MRL-MD-640-1W) was used for irradiating samples/ cells. An optical microscope, EVOS FL, was used for imaging cells and Image software was used to quantify the death ratios of the cells.

\section{Synthesis of GEM-monomer conjugate}

GEM-monomer conjugate 3 was prepared according to our previously reported procedure. ${ }^{38}$ In a $100 \mathrm{~mL}$ one-neck round bottom flask, GEM·HCl 1 (651 mg, 2.17 mmol, 1 eq.), 1-hydroxybenzotriazole (333 mg, $2.17 \mathrm{mmol}, 1 \mathrm{eq}$ ), 1-(3-dimethylaminopropyl)3-ethylcarbodiimide hydrochloride (417 $\mathrm{mg}, 2.17 \mathrm{mmol}$, 1 eq.) and mono-2-methacyloyloxy ethyl succinate 2 (500 mg, $2.17 \mathrm{mmol}, 1$ eq.) were dissolved in dry DMF $(26 \mathrm{~mL})$ and pyridine $(2 \mathrm{~mL})$. The reaction mixture was purged with argon and left at room temperature for $72 \mathrm{~h}$ under a positive Argon atmosphere. The reaction mixture was concentrated under vacuum and ethyl acetate was added $(50 \mathrm{~mL})$. The organic phase was washed with $10 \% \mathrm{NaHCO}_{3}$ aqueous solution $(3 \times 50 \mathrm{~mL})$ and dried over $\mathrm{MgSO}_{4}$. The solution was concentrated under vacuum and the product was purified via column chromatography using DCM : MeOH $(15: 1 \mathrm{v} / \mathrm{v})$ as the mobile phase $\left(R_{\mathrm{f}}\right.$ value of 0.3$)$. The product GEM-monomer conjugate 3 was obtained as a white powder in a $45 \%$ yield $(414 \mathrm{mg}$ ) and was characterized by NMR and mass spectroscopy. ${ }^{1} \mathrm{H}$ NMR $\left(400 \mathrm{MHz}, \mathrm{DMSO}-\mathrm{d}_{6}\right) \delta_{\mathrm{H}}$ (ppm) $1.85\left(\mathrm{t}, J=1.3 \mathrm{~Hz}, 3 \mathrm{H},-\mathrm{CH}_{3}\right), 2.59\left(\mathrm{~m}, 2 \mathrm{H},-\mathrm{O}-\mathrm{C}(\mathrm{O})-\mathrm{CH}_{2}-\right)$, $2.71\left(\mathrm{~m}, 2 \mathrm{H},-\mathrm{CH}_{2}-\mathrm{C}(\mathrm{O})-\mathrm{NH}-\right)$, 3.68-3.79 (m, 2H, $\left.-\mathrm{CH}_{2}-\mathrm{OH}, 2 \mathrm{H}\right)$, $3.90(\mathrm{~m}, 1 \mathrm{H},-\mathrm{CH}-\mathrm{O}-), 4.18(\mathrm{~m}, 1 \mathrm{H},-\mathrm{CH}(\mathrm{OH})-), 4.27$ (s, 4H, $-\mathrm{O}-\mathrm{CH}_{2}-\mathrm{CH}_{2}-\mathrm{O}-$ ), 5.28 (t, $J=5.5 \mathrm{~Hz}, 1 \mathrm{H}, \mathrm{CH}_{2}-\mathrm{OH}$ ), 5.64 (quint, $\left.J=1.6 \mathrm{~Hz} 1 \mathrm{H}, \mathrm{HCH}=\mathrm{C}\left(\mathrm{CH}_{3}\right)^{-}\right), 6.01(\mathrm{dq}, J=2.0,1.0 \mathrm{~Hz}, 1 \mathrm{H}$, $\left.\mathrm{HCH}=\mathrm{C}\left(\mathrm{CH}_{3}\right)^{-}\right), 6.17(\mathrm{t}, J=7.6 \mathrm{~Hz}, 1 \mathrm{H},-\mathrm{C}-\mathrm{CH}=\mathrm{CH}-\mathrm{N}-), 6.29$ (d, $J=6.5 \mathrm{~Hz}, 1 \mathrm{H},-\mathrm{CH}-\mathrm{OH}), 7.22$ (d, $J=7.6 \mathrm{~Hz}, 1 \mathrm{H},-\mathrm{N}-\mathrm{CH}-\mathrm{O})$, 8.22 (d, J = 7.6 Hz, 1H, C-CH=CH-N-), 11.08 (s, 1H, $-\mathrm{C}(\mathrm{O})-\mathrm{NH}-)$; ${ }^{13} \mathrm{C}$ NMR (400 MHz, DMSO-d $\left.{ }_{6}\right) \delta_{\mathrm{C}}(\mathrm{ppm}) 17.9\left(-\mathrm{CH}_{3}\right), 28.0$ $\left(-\mathrm{O}-\mathrm{C}(\mathrm{O})-\mathrm{CH}_{2}-\right), 31.2\left(-\mathrm{CH}_{2}-\mathrm{C}(\mathrm{O})-\mathrm{NH}-\right), 58.8\left(-\mathrm{CH}_{2}-\mathrm{OH}\right), 61.9$ $\left(-\mathrm{O}-\mathrm{CH}_{2}-\mathrm{CH}_{2}-\mathrm{O}-\right)$, $62.4\left(-\mathrm{O}-\mathrm{CH}_{2}-\mathrm{CH}_{2}-\mathrm{O}-\right)$, 68.3 (-CH-OH), 81.0 $\left(-\mathrm{CH}-\mathrm{CH}_{2}-\mathrm{OH}\right), 95.8(-\mathrm{CH}-\mathrm{CH}=\mathrm{CH}-\mathrm{N}-), 122.9(-\mathrm{C}-\mathrm{F}), 126.0$ $\left(\mathrm{CH}_{2}=\mathrm{C}\left(\mathrm{CH}_{3}\right)^{-}\right), 135.5\left(-\mathrm{C}\left(\mathrm{CH}_{3}\right)=\mathrm{CH}_{2}\right), 144.7(-\mathrm{CH}=\mathrm{CH}-\mathrm{N}-)$, $154.1(-\mathrm{N}-\mathrm{C}(\mathrm{O})-\mathrm{N}), 162.7(-\mathrm{NH}-\mathrm{C}=\mathrm{N}-), 166.3(-\mathrm{C}(\mathrm{O})-\mathrm{O}-), 171.9$ $\left(-\mathrm{CH}_{2}-\mathrm{O}-\mathrm{C}(\mathrm{O})-\mathrm{CH}_{2}\right), 172.7(-\mathrm{C}(\mathrm{O})-\mathrm{NH}-)$; LCMS (ESI) $m / z:[\mathrm{M}+\mathrm{H}]^{+}$ 476.15 (calculated); 476.10 (found).

\section{RAFT polymerization of the GEM-monomer conjugate (DP =100)}

In a $10 \mathrm{~mL}$ one-neck round-bottom flask, GEM-monomer conjugate 3 (109 mg, $0.229 \mathrm{mmol}, 100$ eq.), CTA 4 (0.6 mg, $0.023 \mathrm{mmol}, 1$ eq.) and ACVA $(0.128 \mathrm{mg}, 0.0005 \mathrm{mmol}, 0.2 \mathrm{eq}$. were dissolved in DMF $(0.5 \mathrm{~mL})$. The flask was sealed with a rubber septum and purged using argon for $15 \mathrm{~min}$. The flask was heated at $70{ }^{\circ} \mathrm{C}$ for $8 \mathrm{~h}$ under magnetic stirring. The reaction was stopped by exposing the solution to open air and the polymer/ monomer mixture was precipitated using diethyl ether $(5 \mathrm{~mL})$. The residual monomer was washed away using methanol $(3 \times 5 \mathrm{~mL})$ and the polymer was dried under vacuum. The polymer 5 was obtained as a slight yellow powder in a yield of $81.2 \%(89 \mathrm{mg})$ and was characterized using NMR spectroscopy (Fig. S3, ESI $\dagger$ ) and SEC (Fig. S4, ESI $\dagger$ ).

\section{Preparation of spherical gold nanoparticles (GNPs)}

A solution of gold(III) chloride trihydrate $\left(0.4 \mathrm{mg} \mathrm{mL}^{-1}\right)$ was prepared using distilled water and was heated to $70{ }^{\circ} \mathrm{C} .7 .5 \mathrm{~mL}$ of an aqueous solution of trisodium citrate $\left(10 \mathrm{mg} \mathrm{mL}^{-1}\right)$ was added and the mixture was left under magnetic stirring for $30 \mathrm{~min}$. A change in colour was observed; from a slight yellow to a bright ruby colour indicating the successful preparation of spherical gold nanoparticles (GNPs), which were further characterised using UV-vis spectrophotometry and DLS.

\section{Formation of the hybrid nanoparticles}

The GEM-polymer conjugate ( $5 \mathrm{mg}$ ) was dissolved in acetone and mixed with an aqueous GNP solution $\left(0.2 \mathrm{mg} \mathrm{mL}^{-1}\right)(1: 1 \mathrm{v} / \mathrm{v}$, $10 \mathrm{~mL}$ ) in a $12 \mathrm{~mL}$ sample vial flask. Subsequently, 2-fold dilutions were prepared using the same acetone/GNP mixture with the concentration of polymer ranging from $1 \mathrm{mg} \mathrm{mL}{ }^{-1}$ to $2 \mu \mathrm{g} \mathrm{mL} \mathrm{m}^{-1}$ (S1 to S10). For dilution number 4, 6, 7 and 8, another set of samples $\left(\mathrm{S} 4^{\prime}, \mathrm{S}^{\prime}, \mathrm{S}^{\prime}\right.$ and $\left.\mathrm{S} 8^{\prime}\right)$ were prepared where the concentration of GNPs was increased by a factor 2 . For each sample, acetone was removed using a rotor evaporator under controlled conditions (100 rpm, $100 \mathrm{mBar}, 40{ }^{\circ} \mathrm{C}$ ). The hydrid NPs of each sample were characterised using DLS, UV-vis spectrophotometry and TEM.

\section{Evaluation of the colloidal stability of the hybrid NPs}

The hybrid NPs of each sample (S1 to $\mathrm{S} 10$ and $\mathrm{S} 4^{\prime}, \mathrm{S} 6^{\prime}, \mathrm{S} 7^{\prime}$ and $\left.\mathrm{S} 8^{\prime}\right)$ were left at room temperature. After 16 days, the size and dispersity of the hybrid NPs were measured using DLS.

\section{Evaluation of the thermal effect}

Hybrid NPs of sample S7', the GNP suspension and distilled water $(1 \mathrm{~mL})$ were irradiated using a $640 \mathrm{~nm} \mathrm{CW}$ laser for $10 \mathrm{~min}\left(0.8 \mathrm{~W} \mathrm{~cm}^{-2}\right)$ and left to cool for another $10 \mathrm{~min}$. The concentration of Hybrid NPs of Sample $S 7^{\prime}$ and the GNP solution was adjusted in order to have their absorption maxima equal at their respective wavelengths. The temperature of the samples was recorded every minute for 20 minutes and was plotted as a function of the time.

\section{Cytotoxicity assay}

Determination of half-maximal inhibitory concentration $\left(\right.$ IC $\left._{50}\right)$. In a 96 well-plate, $200 \mu \mathrm{L}$ of fresh medium (i.e. DMEM containing $10 \%$ FBS, $1 \%$ glutamine, $1 \%$ penicillin) containing $3 \times 10^{3}$ MiaCaPa- 2 cells was plated in each well and incubated for $24 \mathrm{~h}$ at $37{ }^{\circ} \mathrm{C}$ in a $5 \% \mathrm{CO}_{2}$ atmosphere. Then, $200 \mu \mathrm{L}$ of the medium of each well was replaced with $200 \mu \mathrm{L}$ of fresh medium as a positive control or freshly prepared solution containing GEM-HCl, GEM-monomer conjugate NPs, GNPs and hybrid NPs of Sample S7' with final GEM and GNP concentrations ranging from 0.2 to $7.63 \times 10^{-3} \mu \mathrm{g} \mathrm{mL} L^{-1}$ and from 50 to $0.2 \mu \mathrm{g} \mathrm{mL}{ }^{-1}$, respectively. The cells were further incubated for $72 \mathrm{~h}$; subsequently, the total amount of media was removed and replaced with a $2 \%$ Resazurin $(C)$ solution $(180 \mu \mathrm{L}$, in each well). As a negative control, $180 \mu \mathrm{L}$ of $2 \%$ Resazurin (C) solution was plated without containing cells in the wells. The 96-well plate was incubated for $2 \mathrm{~h}$ and the optical absorbance of each well was 
measured at $570 \mathrm{~nm}$ and $600 \mathrm{~nm}$ using a micro plate reader. Hence, the viability of cells (\%) was calculated using eqn (1) as a function of GEM concentration. The same procedure was repeated except that after $48 \mathrm{~h}$ of incubation with the different formulations, each well was irradiated using a $640 \mathrm{~nm}$ laser for $1 \mathrm{~min}$ $\left(1.4 \mathrm{~W} \mathrm{~cm}^{-2}\right)$. These experiments were performed in triplicate.

$$
\text { Cell viability }(\%)=\frac{A-B}{C-B} \times 100
$$

where $A, B$ and $C$ are the differences in optical absorbance at 570 and $600 \mathrm{~nm}$ of each well containing the formulation (GEM·HCl, GNPs, GEM-monomer conjugate and hybrid NPs), the $2 \%$ resazurin (C) solution (negative control) and only the cells (positive control), respectively.

Apoptosis and necrosis quantification. In a 96 well-plate, $200 \mu \mathrm{L}$ of fresh medium (i.e. DMEM containing 10\% FBS, $1 \%$ glutamine, $1 \%$ penicillin) containing $1 \times 10^{3}$ MiaCaPa- 2 cells was plated in each well and incubated for $24 \mathrm{~h}$ at $37{ }^{\circ} \mathrm{C}$ in a $5 \%$ $\mathrm{CO}_{2}$ atmosphere. Then, $200 \mu \mathrm{L}$ of the medium of each well was replaced with $200 \mu \mathrm{L}$ of freshly prepared solution containing GEM-HCl, GEM-monomer conjugate NPs, GNPs and hybrid NPs of Sample $\mathrm{S7}^{\prime}$ at their $\mathrm{IC}_{50}$. The cells were further incubated for $72 \mathrm{~h}$; subsequently, the total amount of media was removed and cells were washed twice with PBS. The staining solution (i.e. $5 \mu \mathrm{L}$ of Annexin V solution, $5 \mu \mathrm{L}$ of Ethidium Homodimer solution and $100 \mu \mathrm{L} 1 \times$ binding buffer) was added and the cells were incubated for $15 \mathrm{~min}$ protected from light. The staining solution was removed and cells were washed with $1 \times$ binding buffer. The cell fluorescence was recorded using EVOS FL and ImageJ software was used to quantify the necrosis and apoptosis. Furthermore, microscopic images of the cells that were incubated with the hybrid NPs and GNPs were recorded and imageJ software was used to quantify the GNP binding/uptake per cell. More precisely, the GNPs were thresholding in red and the total red signal area was measured in pixel units.

\section{Conclusions}

Overall, we presented a simple, well-defined and dual functional nanoformulation for the treatment of pancreatic cancer cells based on a gemcitabine polymer conjugate that could effectively encapsulate GNPs in an aggregated state to exert redabsorbing characteristics. We showed that various parameters of the formulation such as the size, and the optical properties can be adjusted by simple preparation routes. The hybrid NPs could exert a synergistic photochemotherapeutic effect under therapeutically relevant conditions and also fulfil certain desirable formulation characteristics such as simplicity in preparation, very high drug loading, colloidal stability, and photothermal properties, which we believe render our approach promising for nanomedicinal formulations for pancreatic cancer.

\section{Conflicts of interest}

There are no conflicts to declare.

\section{Acknowledgements}

This study was funded by the Engineering and Physical Sciences Research Council (EPSRC, EP/M014649/1; GP, FJ). We thank the UCL Excellence Fellowship award (GP).

\section{References}

1 O. E. Rahma, A. Duffy, D. J. Liewehr, S. M. Steinberg and T. F. Greten, Ann. Oncol., 2013, 24, 1972-1979.

2 D. Ansari, B. Tingstedt, B. Andersson, F. Holmquist, C. Sturesson, C. Williamsson, A. Sasor, D. Borg, M. Bauden and R. Andersson, Future Oncol., 2016, 12, 1929-1946.

3 H. Oettle, P. Neuhaus and A. Hochhaus, et al., JAMA, J. Am. Med. Assoc., 2013, 310, 1473-1481.

4 C. M. Galmarini, J. R. Mackey and C. Dumontet, Leukemia, 2001, 15, 875-890.

5 R. Andersson, U. Aho, B. I. Nilsson, G. J. Peters, M. PastorAnglada, W. Rasch and M. L. Sandvold, Scand. J. Gastroenterol., 2009, 44, 782-786.

6 E. Moysan, G. Bastiat and J.-P. Benoit, Mol. Pharmaceutics, 2013, 10, 430-444.

7 A. Manzur, A. Oluwasanmi, D. Moss, A. Curtis and C. Hoskins, Pharmaceutics, 2017, 9, 39.

8 H. Cabral, Y. Matsumoto, K. Mizuno, Q. Chen, M. Murakami, M. Kimura, Y. Terada, M. R. Kano, K. Miyazono, M. Uesaka, N. Nishiyama and K. Kataoka, Nat. Nanotechnol., 2011, 6, 815-823.

9 W. Wang, C. Li, J. Zhang, A. Dong and D. Kong, J. Mater. Chem. B, 2014, 2, 1891-1901.

10 D. Trung Bui, A. Maksimenko, D. Desmaële, S. Harrisson, C. Vauthier, P. Couvreur and J. Nicolas, Biomacromolecules, 2013, 14, 2837-2847.

11 D. Chitkara, A. Mittal, S. W. Behrman, N. Kumar and R. I. Mahato, Bioconjugate Chem., 2013, 24, 1161-1173.

12 V. Khare, S. Kour, N. Alam, R. D. Dubey, A. Saneja, M. Koul, A. P. Gupta, D. Singh, S. K. Singh, A. K. Saxena and P. N. Gupta, Int. J. Pharm., 2014, 470, 51-62.

13 H. Song, H. Xiao, M. Zheng, R. Qi, L. Yan and X. Jing, J. Mater. Chem. B, 2014, 2, 6560-6570.

14 M. Vandana and S. K. Sahoo, Biomaterials, 2010, 31, 9340-9356.

15 T. J. Liang, Z. M. Zhou, Y. Q. Cao, M. Z. Ma, X. J. Wang and K. Jing, Int. J. Pharm., 2016, 513, 564-571.

16 L. Zou, H. Wang, B. He, L. Zeng, T. Tan, H. Cao, X. He, Z. Zhang, S. Guo and Y. Li, Theranostics, 2016, 6, 762-772.

17 X.-M. Zhu, C. Fang, H. Jia, Y. Huang, C. H. K. Cheng, C.-H. Ko, Z. Chen, J. Wang and Y.-X. J. Wang, Nanoscale, 2014, 6, 11462-11472.

18 X. Huang, S. Tang, X. Mu, Y. Dai, G. Chen, Z. Zhou, F. Ruan, Z. Yang and N. Zheng, Nat. Nanotechnol., 2011, 6, 28-32.

19 Q. Tian, M. Tang, Y. Sun, R. Zou, Z. Chen, M. Zhu, S. Yang, J. Wang, J. Wang and J. Hu, Adv. Mater., 2011, 23, 3542-3547.

20 S. S. Chou, B. Kaehr, J. Kim, B. M. Foley, M. De, P. E. Hopkins, J. Huang, C. J. Brinker and V. P. Dravid, Angew. Chem., Int. Ed., 2013, 52, 4160-4164. 
21 J. T. Robinson, S. M. Tabakman, Y. Liang, H. Wang, H. Sanchez Casalongue, D. Vinh and H. Dai, J. Am. Chem. Soc., 2011, 133, 6825-6831.

22 X. He, X. Bao, H. Cao, Z. Zhang, Q. Yin, W. Gu, L. Chen, H. Yu and Y. Li, Adv. Funct. Mater., 2015, 25, 2831-2839.

23 J. R. Lepock, K.-H. Cheng, H. Al-qysi, I. Sim, C. J. Koch and J. Kruuv, Int. J. Hyperthermia, 1987, 3, 123-132.

24 J. R. Lepock, H. E. Frey, A. M. Rodahl and J. Kruuv, J. Cell. Physiol., 1988, 137, 14-24.

25 N. S. Abadeer and C. J. Murphy, J. Phys. Chem. C, 2016, 120, 4691-4716.

26 X. Huang, P. K. Jain, I. H. El-Sayed and M. A. El-Sayed, Lasers Med. Sci., 2008, 23, 217-228.

27 X. Wu, L. Zhou, Y. Su and C.-M. Dong, J. Mater. Chem. B, 2016, 4, 2142-2152.

28 C. Du, J. Qian, L. Zhou, Y. Su, R. Zhang and C.-M. Dong, ACS Appl. Mater. Interfaces, 2017, 9, 31576-31588.

29 D. Wang, Z. Xu, H. Yu, X. Chen, B. Feng, Z. Cui, B. Lin, Q. Yin, Z. Zhang, C. Chen, J. Wang, W. Zhang and Y. Li, Biomaterials, 2014, 35, 8374-8384.

30 Z. Zhang, J. Wang, X. Nie, T. Wen, Y. Ji, X. Wu, Y. Zhao and C. Chen, J. Am. Chem. Soc., 2014, 136, 7317-7326.

31 T. Sun, Y. Wang, Y. Wang, J. Xu, X. Zhao, S. Vangveravong, R. H. Mach and Y. Xia, Adv. Healthcare Mater., 2014, 3, 1283-1291.

32 J. Peng, T. Qi, J. Liao, B. Chu, Q. Yang, Y. Qu, W. Li, H. Li, F. Luo and Z. Qian, Theranostics, 2014, 4, 678-692.

33 E. A. K. Nivethaa, S. Dhanavel, V. Narayanan, C. A. Vasu and A. Stephen, $R S C A d v .$, 2015, 5, 1024-1032.

34 D. Cassano, M. Santi, V. Cappello, S. Luin, G. Signore and V. Voliani, Part. Part. Syst. Charact., 2016, 33, 818-824.

35 J. Wan, J.-H. Wang, T. Liu, Z. Xie, X.-F. Yu and W. Li, Sci. Rep., 2015, 5, 11398.

36 R. van der Meel, T. Lammers and W. E. Hennink, Expert Opin. Drug Delivery, 2017, 14, 1-5.
37 K. Raemdonck and S. C. De Smedt, Nat. Biotechnol., 2015, 33, 1026-1027.

38 F. Joubert, L. Martin, S. Perrier and G. Pasparakis, ACS Macro Lett., 2017, 6, 535-540.

39 J. Turkevich, P. C. Stevenson and J. Hillier, Discuss. Faraday Soc., 1951, 11, 55-75.

40 L. M. Demers, M. Östblom, H. Zhang, N.-H. Jang, B. Liedberg and C. A. Mirkin, J. Am. Chem. Soc., 2002, 124, 11248-11249.

41 C. R. Patra, R. Bhattacharya, E. Wang, A. Katarya, J. S. Lau, S. Dutta, M. Muders, S. Wang, S. A. Buhrow, S. L. Safgren, M. J. Yaszemski, J. M. Reid, M. M. Ames, P. Mukherjee and D. Mukhopadhyay, Cancer Res., 2008, 68, 1970-1978.

42 M. Mammen, S.-K. Choi and G. M. Whitesides, Angew. Chem., Int. Ed., 1998, 37, 2754-2794.

43 X. Liu, B. Li, F. Fu, K. Xu, R. Zou, Q. Wang, B. Zhang, Z. Chen and J. Hu, Dalton Trans., 2014, 43, 11709-11715.

44 M. Sun, F. Liu, Y. Zhu, W. Wang, J. Hu, J. Liu, Z. Dai, K. Wang, Y. Wei, J. Bai and W. Gao, Nanoscale, 2016, 8, 4452-4457.

45 T.-C. Chou and P. Talalay, Trends Pharmacol. Sci., 1983, 4, 450-454.

46 J.-L. Li and M. Gu, Biomaterials, 2010, 31, 9492-9498.

47 J. R. Melamed, R. S. Edelstein and E. S. Day, ACS Nano, 2015, 9, 6-11.

48 C. Tortiglione and R. Iachetta, Ann. Transl. Med., 2016, 4, S51.

49 P. Cherukuri, E. S. Glazer and S. A. Curley, Adv. Drug Delivery Rev., 2010, 62, 339-345.

50 B. Hildebrandt, P. Wust, O. Ahlers, A. Dieing, G. Sreenivasa, T. Kerner, R. Felix and H. Riess, Crit. Rev. Oncol. Hematol., 2002, 43, 33-56.

51 T. R. Barlow, J. C. Brendel and S. Perrier, Macromolecules, 2016, 49, 6203-6212. 